\title{
Conciliación y revelación en el concepto de Pietät de Hegel: humanismo de la comunidad
}

\section{Conciliation and revelation in Hegel's concept of Pietät: humanism of community}

Adolfo Lizárraga-Gómez (adolfo.lizarraga@umich.mx) Facultad de Economía, Universidad Michoacana de San Nicolás de Hidalgo (Michoacán, México). https://orcid.org/0000-0003-30303283

\begin{abstract}
This article highlights the fundamental place that Hegel gives to the concept of Pietät in the ethical conformation of the Western community and its influence on social thought. Based on the Hegelian thesis of the artistic-religious origin of philosophy, this work locates concept of Pietät in the reading that Hegel made of Sophocles' Antigone. Which is why this article is guided by three structuring concepts: law, revelation, and conciliation, standing out the radical site of women in the humanization of civilization, so it is built on two general parts: the preponderantly male exposure and the arriving to a female approach as a try of overcome philosophy. It is why this writing leans on the interpretation some social researchers have made of Hegelian's reading of Antigone and concludes that the concept of Pietät makes a fundamental framework to Hegel's thought to reveal the substantial human-communitary component of modern civilization.
\end{abstract}

Key words: Pietät, revelation, conciliation, tragedy, community.

\section{Resumen}

Este artículo destaca el lugar fundamental que Hegel da al concepto de Pietät en la conformación ética de la comunidad occidental y su influencia en el pensamiento social. Con base en la tesis hegeliana del origen artístico-religioso de la filosofía, el artículo ubica la Pietät en la lectura que Hegel hizo de la Antígona de Sófocles, y se guía por tres conceptos estructurantes: ley, revelación y conciliación, destacando el lugar radical de la mujer en la humanización de la comunidad, por lo que se conforma en dos partes generales: la exposición preponderantemente masculina y el arribo al planteamiento femenino como intento de superación de la filosofía. Por ello, este trabajo se apoya en la interpretación que hacen algunos pensadores sociales de la lectura hegeliana de la Antígona y concluye que el concepto de Pietät constituye un marco fundamental para el pensamiento de Hegel para revelar el componente sustancial humano-comunitario de la civilización moderna.

Palabras clave: Pietät, revelación, conciliación, tragedia, comunidad. 


\section{Introducción}

Según Marcuse (Razón y revolución) la sociología positivista en sus orígenes concibió que el de Hegel era el pensamiento negativo al que habría que contraponer el novedoso pensamiento social científico. Hegel concebía al Estado y la sociedad como obras humanas, la sociología positivista como producto de leyes objetivas. Recientemente, Judith Butler (Warum jetzt Hegel lesen) afirmó que Hegel recupera un individuo-social humano. Butler concibe la obra de Hegel como pensamiento social básico para explicar fenómenos recientes como los de la migración, derechos humanos, etc.

Con su concepto de Pietät ligado a su lectura de la Antígona de Sófocles, Hegel guía hacia la ética como enlace sustancial de los individuos y confronta al universalismo especulativo y científico positivista objetivista (cuyo evolucionismo atrapó incluso al marxismo) y al uso del estructuralismo en temas como la distribución de roles en la vida social visto desde la perspectiva de género en particular. Esta confrontación acontece destacadamente desmitificando la religión y el arte y, así, el empeño realista fenoménico positivista por encontrar lo que Heidegger identificó como verdad escolástica: veritas adaequatio rei ad intellectum. Las vertientes evolucionistas y antropológicoestructuralistas, presas de ese realismo, consciente o inconscientemente desarrollan un nihilismo mediante métodos de pensar a la sociedad suponiendo el ejercicio de los valores de libertad y justicia y restando espacio al de fraternidad que esconde un humanismo que se descubre en los sentimientos y manifiesta la consciencia de que los individuos actúan en sí y para sí al buscar solución a problemas sociales. En suma, Hegel adelanta un radical marco conceptual para el estudio de la realidad social desde un humanismo que se esconde en las acciones éticas y políticas que se traducen en formas de comunidad y sociedad y que es posible descubrir con la filosofía como herramienta desentrañante.

La filosofía, dice Hegel en su Enciclopedia de las ciencias filosóficas, es, por consiguiente, la unidad del arte y la religión. Con mayor precisión: "la filosofía se determina a sí misma al conocimiento de la necesidad del contenido de la representación absoluta, así como al conocimiento de la necesidad de las dos formas, a saber, de la intuición inmediata y su poesía por un lado, y de la representación que supone por el otro, o sea, de la revelación objetiva y exterior; primero, de su subjetivo adentrarse en sí y, luego, del movimiento subjetivo de salida e identificar la fe con lo supuesto" (Hegel 2005:591). Por ello, este artículo tiene presente el origen artístico-religioso de la filosofía, por una parte, $y$, por otra, el concepto fundamental que emerge de esta acción: el de revelación.

Por otra parte, en la edición alemana de Ganz de 1833 de los Principios de filosofía del derecho, escribió Hegel lo siguiente: "Die Pietät wird daher in eine der erhabensten Darstellungen derselben, der Sophokleischen Antigone, vorzugsmeise als das Gesetz des Weibes ausgesprochen, und als das Gesetz der empfindenden subjektiven Substantialität, der Innerlichkeit, die noch nicht ihre vollkommene Berwirklichung erlangt, als das Gesetz der alten Götter, des Unterirdischen, als ewiges Gesetz, von dem niemand wei $\beta$, von wannen es erschien, und im Gegensa $\beta$ gegen das offenbare, das Gesetz des Staates dargestellt; ein Gegensatz, der der höchste sittliche und darum der höchste tragische, und in der Weiblichkeit und Männlichkeit dasselbst individualisiert ist" (Hegel 1833:230).

En esta tesis se observa que "piedad", traducida como Pietät, aparece como punto de partida y marco de una serie de conceptos fundamentales para la obra de Hegel. En primer lugar, refiere al arte y, en particular, a la poesía y destaca a la Antígona de Sófocles. Habla, a continuación, de leyes: 
la femenina (Gesetz des Weibes) es propia de la piedad. Sinteticemos, entonces, la relevancia del concepto de ley en Hegel.

En la Fenomenología del espíritu, Hegel distingue entre la ley universal y su concepto: la primera es propia del "ser sensible"; el concepto va más allá, hasta negar a la ley misma. La ley corresponde en su realización a la unidad particular escenciada y universalizada en tanto conciliación entre contrarios, así, por ejemplo, la electricidad es electricidad negativa y positiva, y el ser adquiere la determinidad (Bestimmtheit) de "existencia en general". Esta existencia adviene por necesidad y por concepto, la superación de la necesidad. Esta superación conceptual aparece, en principio, como supra-sensible, y da lugar a la ley formada por una contraposición entre lo que le es interno y lo que le es exterior, en la medida en que su identidad consigo misma se realiza como diferencia en lo que le es exterior, imponiendo una esencia contradictoria entre lo que es ella y lo que es para otros. La conciliación se logra en la pena que paga cuando su realización constituye la violación de sí misma, ahí alcanza su acabamiento (completud y límite). En este límite, se alcanza la unidad orgánica que pone en cuestión la dicotomía infinito-finito. Lo social es un organismo compuesto por leyes individuales y se forma al conciliar estas diferencias legales que aparecen enfrentándose para conformar su diferencia en comunidad imponiendo una ley general que se universaliza como poder conceptual que se completa en la pena.

La Pietät se representa a sí misma como "ley de la mujer" (Gesetz des Weibes) y se completa ante la "ley del Estado" (Gesetz des Staates) y de los hombres, como su límite exterior, y su límite interior es la "sustancialidad subjetivamente sensible" (der empfindenden subjektiven Substantialität), la espiritualidad (der Innerlichkeit) que no ha alcanzado su perfecta realización. Subterránea (Unterirdisch) se constituye como ley de los viejos dioses (Gesetz der alten Götter), eterna (ewiges Gesetz), desconocida para todos y opuesta a lo abierto, espacio de la "ley del Estado" que, al encontrarlo, representa la más alta contraposición ética humana en la que el concepto de Pietät podría revelar la vía de la conciliación.

Por la complejidad del tema y el espacio del que dispone, este trabajo hace un acercamiento al concepto de Pietät, que expresa ese fundamento humano de lo social, apoyándose y poniendo a prueba algunos estudios filosófico-sociales realizados a la lectura que hizo Hegel de la Antígona, y busca el origen y estructura de ese concepto guiado por los fundamentales conceptos de revelación y conciliación en el marco de la ley de la Pietät y en dos momentos: de lo aparente y dominante (lo masculino), a lo subterráneo (femenino) y substancialmente humano comunitario, poniendo de manifiesto la influencia de Hegel al pensamiento social que lo niega, luego, en un positivismo evolucionista y estructuralista. En un siguiente trabajo, habrá de exponerse directamente en detalle este concepto desde la obra de Hegel.

\section{Tragedia y Pietät}

\section{Pietas y origen secular de la piedad}

En su Estética, Hegel afirma que en la Antígona de Sófocles "todo es consecuente", Antígona, entonces, es un organismo legal. En su esencia particular fraternal, se refiere a los dioses subterráneos y atiende a su substancialidad subjetiva sensible: "como hermana cumple el sagrado deber de la sepultura, según la piedad de su amor hacia el hermano. Para ello, invoca la ley de los 
dioses; pero los dioses que ella venera son los dioses subterráneos del Hades..., los dioses internos del sentimiento, del amor, de la sangre, no los de la luz, y de la libre y autoconsciente vida del pueblo y del Estado" (Hegel 1997:98). La pregunta es ¿qué revela Antígona con esta organicidad legal? La hipótesis es, formalmente, el advenimiento al ser como mera existencia, por una parte y, por otra, actúa para el advenimiento de la substancia propiamente humana reconciliada. Como obra de arte, Antígona tiene un doble objetivo que se une en un ápice: primero, "solo puede ser el de revelar la verdad" (Hegel 1997:98). Y, segundo, acceder "a un punto de vista superior, que es el de la oposición resorbida, de la conciliación de los contrarios. Éste es el objetivo supremo, el objetivo absoluto" (Hegel 1997:100). Y concluye Hegel: "El arte evoluciona en esta esfera, la más elevada que es la de la idea de la conciliación de los contrarios, y este es el punto de vista que vamos a adoptar nosotros en nuestras ulteriores consideraciones acerca del arte" (Hegel 1997:101). El término Versöhnen, traducido indistintamente como "conciliación" y "reconciliación" dirige a un punto de llegada u objetivo final (Zweck, término que también se traduce como "destino"). La segunda pregunta es, pues, cómo se concilia en Antígona.

La respuesta inicia en la búsqueda que Hegel emprende por superar la concepción universal e ideal de Platón del bien, lo bello y lo verdadero, descubriendo determinaciones particulares y concretas: el enlace de lo universal general con "lo particular de la determinación real" (Hegel 1997:98). Aquí aparece la Tragedia.

Ernst Bloch descubre que, en relación directa con el Fedro de Platón, Hegel concibe la tragedia como "la más dialéctica de todas las artes", y que su final es la "reconciliación con la eterna justicia" (Bloch 1983:164). La filosofía ve emerger de la tragedia la substancia subjetiva humanizada, en vez de la objetiva religiosa, y posibilita traer a la luz lo absoluto reconciliado y re-presentado concretamente en un producto particular de la acción individual en su esencia artística. La justicia destaca el encuentro del absoluto re-conciliado en formas de la ética que acontecen en la vida comunitaria que Hegel presenta en su determinación real y constructiva. Bloch ve este absoluto ético en el tránsito de la vida familiar y comunitaria a la del Estado, que describe el desarrollo de "formas sociales" que, en Hegel, aparecen históricamente en obras artístico-religiosas y en diferentes concepciones de la justicia: la de los dioses, es "objetiva" y ajena, la de la justicia aparece en confrontaciones para la realización individual humana mediante luchas con los dioses y entre ellos mismos.

Pérez (Acción y muerte en la Antígona de Hegel) no ve conciliación en esta realización individual, sino conflicto que descubre la substancia individual que se universaliza y da forma a toda la historia humana: la acción, que se concreta en particularidades determinadas y se desarrolla esencialmente como la gran paradoja, la negación de la negación; como obra y negación de sí misma, la acción se auto-concibe en sí y para sí. Según Pérez, Antígona con su proceder ante Creonte vive esta paradoja substancial y la trae a la vista representada en tragedia que avanza concretamente hacia su universalización actualizándose eternamente, por ello la tragedia no desaparece en la obra de Hegel, se manifiesta en la autoconsciencia trascendiendo tiempo y espacio. La contraposición Antígona-Creonte se presenta y refleja en esencias particulares femeninas: Antígona no es mujer en abstracto, es hermana que, al realizar esta esencia con su acción, propicia el tránsito de la ley divina a la ley humana, crea sentido, sustancialidad que se opone, al mismo tiempo, a la muerte donde alcanza su límite y completud y no llega a la reconciliación dialéctica, como muerte de la muerte, que sugiere la fundación de una forma social-comunitaria hegeliana. De esta manera, Pérez 
identifica tragedia con fracaso y sugiere que la interpretación de Hegel de la Antígona presenta el paradigma del fracaso, que se traduciría en fracaso de la humanidad, que para Pérez es la historia de occidente.

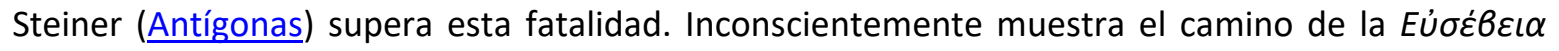
griega a la Pietas latina, que enlazan con la Pietät de Hegel y acción y muerte adquieren un sentido humano-secular. Steiner encuentra la revelación histórico-concreta del drama-tragedia en la Antígona de Garnier, quien utiliza la Pietas haciendo referencia a Virgilio. Garnier publicó su texto en 1580, dimensión histórica que le posibilita, según Steiner, definir la Pietas como unidad entre "devoción" y "compasión" que refleja el humanismo del renacimiento que comparte las verdades cristianas, en particular, el "heroísmo como lucha libremente compartida" (devoción) y la concepción de la "acción como compasión". Este concepto de Pietas cambia la definición aristotélica de piedad: ya no es "temor" y "compasión", como posible reflejo e identidad con el otro y consecución de una "catarsis", la "devoción" representa aislamiento y adentramiento, un en-sí radical que busca encontrar internamente un otro que no él, y confunde ese otro con la deidad, un proceso de enajenación propio de la acción moderna.

Según Steiner, Garnier vio esta Pietas en determinados acontecimientos, y refleja el Logos de su época en tanto palabra: el latín es la lengua cultural (como decía Lorenzo Valla), universalizada por el cristianismo cuya crisis se manifiesta, sobre todo, en la negación de la base familiar rompiendo, así, la sustancia ética básica a la que no le es naturalmente posible su universalización. La Pietas puede migrar, entonces, a otro componente en-sí mismático de la "devoción": la patria, como ocurre en el humanismo, por ejemplo, de Guicciardini. "Patria" permite a la Pietas concebir a la humanidad en su relación inmediata con la tierra y, con ello, al origen. Se forma una sustancialidad más profunda que la acción: la In-humanidad que, como In-humar identifica a la muerte como pervivencia en lo subterráneo y condición esencial de lo humano.

Antígona, la mujer, manifiesta la relación de la humanidad con la sustancialidad divino-terrenal que se contiene en el concepto de Pietas, pues de ella proviene Dios hecho Hombre y la humanidad que proviene del vientre materno es el "hijo del Hombre", de esta forma se concreta la in-humación en el seno de la humanidad. La mujer se torna lo particular y de esa esencia se fortalece una concepción secular de la humanidad ligada a la piedad en la cultura occidental, en la que naturaleza y divinidad se conjuntan como propiedad humana. La tragedia dibuja una historia universal particular.

La piedad, en suma, tiene atributos que poseen los individuos que se revelan como humanos superando (en el sentido de negar conservando de Hegel) progresivamente el componente religioso. Al individuo-humano solo le es posible vivir mediante la acción haciendo patente la contradicción sustancial que Steiner concibe como "sensible fragmentación de lo absoluto": la convivencia entre contrarios. Para Steiner esta "sensible fragmentación de lo absoluto" es la dinámica que traza la historia humana. Es un absoluto de este mundo, un mundo limitado, contingente, específico, individual, en el que se reproducen las formas reales de lo universal ético, que apunta hacia el hogar, lo familiar.

Este absoluto mundano estrecha la relación de la ley divina con la humana desde su ámbito natural e inconsciente y concluye su representación en el pueblo y la tierra, partiendo de la familia en tanto comunidad natural que completa su identidad en la realidad social. La raíz de la familia es ontológica 
con una sustancia ética que habrá de diferenciarse, todavía, en su relación con la muerte desde la perspectiva de la tierra como entierro. Pero, a la vez que se identifica con lo terreno, esta raíz abre un concepto de Gemeinwesens que supera la concepción del individuo como fuerza física en tanto medida inicial de poder. Steiner no identifica esta potencialidad individual con la acción en tanto Handlung que, en Hegel, acerca a la configuración comunitaria desde el poder colectivo mediante el cual es humanamente posible superar fuerzas exteriores, describiendo, así, la superación ética de la moral. Ésta se atiene a lo divino y se impone objetivamente, aquella apela a la acción y subjetiva.

Steiner ve en el discurso de Hegel sobre ética que la contradicción entre Creonte y Antígona representa la que habría entre política y ontología. La política se manifiesta parcializada, apegada a una nación y es objetiva. La ontológica es consciente y revela la individualidad que Hegel concibe como auto-posesión que se torna auto-consciencia sobre la base de leyes eternas y universales de las cuales Antígona aparece como portadora. En su análisis de la tragedia, Hegel habría descubierto y descrito una contraposición que presenta como evolución histórica (como vimos con Bloch) conectada con una comprensión ética en sus "representaciones" como familia, sociedad civil y Estado. En estas representaciones, para Steiner, lo esencialmente individualizable es la acción como medio efectivo de traer a la luz, y en esto supera el planteamiento de Pérez citado; el propósito de la acción es la existencia como "advenimiento al ser", que se advierte en el concepto hegeliano de ley. Este advenimiento tiene como propósito irrenunciable el de traer la individualidad de la que brota la sustancialidad universal en su forma de Sittlichkeit mediante la que el individuo pone a la luz, incluso involuntariamente, la comunidad. Este universal solo puede hacerse presente en el individuo como entidad humana concreta y portadora de una esencia que no puede diferenciarse en múltiples y mutables esencias, sino que es igual a sí misma. Hegel, según Steiner, ve en Antígona la transparencia del individuo que expresa su universal de forma inocentemente esencial y, por ello, se auto-pone ante el juicio, logrando esa mutabilidad de lo universal que expone a la humanidad misma, a la vez que la cuestiona y posibilita su curso por la piedad, revelando, por una parte, que la humanidad es mortal y solo puede acceder a la inmortalidad fuera de este mundo en el humanodivino de los muertos. De esta manera, la muerte no es definitivo perecer, como sugiere Pérez, sino un resurgir reconciliante del individuo con lo universal en la comunidad en la que conforma un espíritu reconciliado consigo mismo.

Lukács (El joven Hegel) trata esta reconciliación mortal desde dos conceptos: "tragedia de lo ético" y propiedad, en esta última se alcanza la reconciliación mediante el camino que aquella traza. La tesis principal de Lukács es: la negación individual de su pertenencia a lo social, es anti-natura y una manifestación de auto-alienación, pues la humanidad se desprende de sí misma orgánicamente. En la tragedia se revela esta amenaza a la humanidad como confrontación entre lo subterráneo y natural y su superación en la luz. Para Lukács es una confrontación entre "sub-esencias del espíritu" que buscan superarse en ese encuentro contradictorio, y su conclusión o acabamiento es la superación de la tragedia. Esta confrontación hace de la ética una víctima, al poner en cuestión al individuo que la porta y representa a la vez que posibilita su superación. Este cuestionamiento al individuo se impone en la tragedia como desafío y dicha superación se alcanza en la comunidad, en tanto es la única que posibilita la libertad individual y pone de manifiesto al individuo en sus potencialidades, es decir, esencialmente.

Siguiendo a Marx, Lukács concibe que la comunidad se determina por cierta forma de relaciones sociales generales que, en el occidente moderno, producen en la humanidad un reduccionismo 
propio de la tragedia de la ética. Este reduccionismo produce un tipo de comunidad que se generaliza y toca a las íntimas relaciones familiares, y a la que las formas de expresión comunitaria oponen una resistencia que se expresa en la tragedia. La familia expresa su resistencia a las formas modernas de universalización desde la sensibilidad como vía hacia lo natural-humano. La naturalidad humana en la familia toca lo biológico y la unidad dialéctica infinita de lo orgánico y lo inorgánico como su única posibilidad de vida. La familia reorienta lo "trágico de lo ético" constantemente hacia lo orgánico-natural con destino a la reconciliación. En este propósito, lo orgánico-familiar se re-dirige a lo pre-sentimental situándose en la forma de sociedad en la cual se forja una forma de eticidad y universalidad, y desciende, así, al origen del sentimiento. En el encuentro de lo natural y lo sentimental, se va delimitando un concepto de "piedad" que se diferencia de lo religioso, permitiendo concebir progresivamente un organismo (naturaleza) que se concilia con lo inorgánico (las representaciones esenciales del sentimiento).

Lukács cree descubrir en Hegel una nueva sub-terrenidad: el origen natural de lo social que impregna lo aparente o "mundo de la luz". En esta organicidad social se inicia la imposición de una ética que se conforma en la vida estatal e impone, luego, una nueva universalidad que, a su vez, convive contradictoriamente con la sub-terrenidad que pervive y emerge a la superficie luchando por el dominio de la universalidad absoluta. En esta lucha se concibe la propiedad desde lo orgániconatural que va ascendiendo hacia lo orgánico-social. Y con el concepto de propiedad se muestra en la base orgánico-natural el trabajo que, luego, se torna fundamento de toda organicidad-social. El trabajo realiza la propiedad natural-social de los individuos, su pertenencia a un universal forjado en una comunidad re-evolucionada.

Siguiendo a Hegel, Lukács concibe al trabajo como actividad natural y pre-sentimental a la que la modernidad impone su ética como sustancia universal, obligándolo a contraponerse a su origen natural orgánico y su propiedad humana. Es un proceso de enajenación y des-organicidad que se reorganiza en un objeto en el que tiene lugar una "tragedia de lo ético" que se impone al individuo en el mundo estatal moderno. Esta imposición social moderna a la naturalidad orgánica, se acerca a la crítica que Hegel hace a la religión y arte asiáticos, que opone un Dios a la humanidad que no le es orgánicamente propio, la despoja de voluntad y adquiere representación artística en el simbolismo que será superado por el arte clásico-griego. La objetivación del trabajo en la sociedad occidental moderna aparece como riqueza material que posibilita el aislamiento en forma de egoísmo y la anticomunidad determinando (legalmente) la esencia del trabajo como productor de riqueza objetiva y concreta y la "tragedia de lo ético" traducida en vida social-estatal moderna.

La "tragedia de lo ético" como proceso de des-organicidad e imposición de valores objetivoeconómicos, para Lukács, es lo que hace que Hegel busque la humanidad en su pureza; Antígona como piedad alude al origen orgánico-natural de los individuos cuya conciliación se re-presenta en comunidad, superando el carácter y esencia religiosos de su substancia. La modernidad puede ser pensada desde este origen substancial en tanto que la civilización impone valores novedosos que se sostienen sobre una base económica y se dirigen a una re-conciliación determinada. El Estado institucionaliza y soporta esos valores que, aunque sustituyen radicalmente a la naturaleza y la comunidad primeras, siguen siendo humanos, lo cual posibilita lo positivo de la negación objetivista de aquella substancia orgánica original y, por lo tanto, auspicia la re-conciliación: tiene lugar en la raíz de la comunidad una lucha que solo la inconsciencia puede negar. Los contrarios en esta negación de la negación son puestos en evidencia por la tragedia en su forma artística y es la piedad 
lo que posibilita traer a la luz, desde la inconsciencia, la posible positividad de ese encuentro contradictorio, como el que se da entre Creonte y Antígona. Esta revelación de la lucha de contrarios es la verdad que solo puede ser re-ocultada y remitida a lo subterráneo, mediante una confrontación fundamental de la tragedia con la comedia y la sátira.

Lukács, en suma, concibe, como Pérez, que Hegel no abandona la tragedia, pero al alejarse de lo religioso, la revelación y la reconciliación son plenamente seculares y de ellas surge la piedad a la luz. Es posible, como afirma Ginzo, que Hegel haya encontrado en la religión protestante el acceso a esta reconciliación que, como sugiere Lukács, represente a la humanidad en su pureza desde la subjetivación.

\section{Piedad y subjetivación}

Según Ginzo ( los siguientes principios: el humanismo es una forma individual de vida y asume que la libertad del individuo funda la vida social, incluida su religión. La vida humana en tanto obra propia permite ver al individuo con claridad en el ejercicio de sus potencialidades, aunque se presente en una racionalidad negativa. Estas potencialidades incluyen la complejización de su forma de concebir sus obras desde el pensamiento, como reposicionamiento constante de su voluntad en su vida cotidiana y concibe a Dios como apoyo, pero no como a quien se debe la vida humana. La primera referencia de la humanización del individuo es concebir que la vida es como la piensa.

El protestantismo permite concebir que la forma natural más abstracta es el sentimiento que aparece como "testimonio del espíritu" y acontece mediante la naturalización del espíritu que, al perder la espiritualidad abstracta de lo humano, evoluciona, en principio, al concepto en cuanto pensamiento, cuyo resultado es su auto-situación en el tiempo y espacio a cuya construcción contribuye. Una vez dado este encuentro con el presente, es posible elevarse hacia Dios y al Estado, desde la ley divina a la ley humana, y en esta evolución en la modernidad occidental el sentimiento aparece como aspiración humana a materializarse en el concepto. Este encuentro de religión y política es una acción autoconsciente que tiene lugar en épocas en las que lo humano se sitúa más concreta y específicamente en la consciencia y que es posible advertir en la tragedia en general y en la Antígona de Sófocles en particular: religión y política se fundan en este mundo reflejadas en la acción de individuos concretos dotados de sustancia, es decir, como representaciones. La religión solo puede hacerse presente en el concepto. El pensamiento trasciende, así, de la religión a la filosofía. Antígona presenta esta coherencia que conduce al pensamiento: el individuo, en abstracto, transita de lo religioso (representado en su esencia de mujer, Antígona) al pensamiento propiamente humano (en su esencia de hombre, Creonte) dirigido hacia el Estado. El concepto y el pensamiento guían hacia el saber haciendo de lo espiritual una entidad cada vez más humana sensible, a la que se puede asir. El saber se torna en producto de un proceso y devenir constantes que participan en la acción humana y lleva a otro producto fundamental: la subjetividad.

El individuo se crea y porta una sustancia que domina e impulsa su individualidad y que, a su vez, posee y adecúa desde el pensamiento. Este que aparece como proceso interior y propio del individuo, propende a una configuración efectiva y real del encuentro de lo objetivo con lo subjetivo y se manifiesta en el exterior del propio individuo transformador de su individualidad y en lo que aprende para su propia esenciación. La individualidad va tornándose subjetividad desde su 
encuentro con lo objetivo exterior al individuo que, con su acción, concibe una nueva objetividad. La objetividad aparece ante el individuo abstracto y, luego, como producto de esa relación ocupa en esa abstracción el lugar de lo universal; la subjetivización, como individualización de lo universal, en este proceso de objetivización-universalización es, a la vez, contradictoriamente, subjetivizaciónindividualización. La nueva objetivación que resulta de esta unidad contradictoria aparece como la absoluta-totalidad, en la que, a la vez, quedan liberados los tres componentes estructurales: lo universal, la individualidad y la unidad de ellos en una nueva objetividad que, a su vez, sujeta la unidad de contrarios.

Coincidiendo con Lukács, Ginzo plantea que la nueva objetividad y sujeción producidas por las acciones individuales en su esencia de trabajo da lugar a la formación humana, produce nuevas entidades y un sí-mismo novedoso. El trabajo es humanización del trabajador y su entorno y forma un deber ser en una dimensión que diferencia a la moral de la ética: la libertad de las potencias humanas que se concretan en una actividad totalizadora, un proceso de formación que sujeta y dessujeta a la vez yendo al origen en un retorno a la raíz que no es conservarse en ella, proceso de abstracción y replanteamiento de sí mismo. Acontece un proceso de auto-objetivación y alienación, como Er-innerinung y no Ent-äuserung, que se representa como actuar en sí mismo para otro, un compartir. Este proceso de auto-abstracción es un efectivo para sí mismo, que actúa para liberarse de su auto-sujeción. En este proceso de liberación de sí mismo para otros entra en crisis la universalización y la individualización, pues el individuo se presenta ante lo universal como proceso trascendental.

La universalización debida al trabajo en su forma moderna es potencialmente comunitaria y social y adquiere, así, posibilidades de incursionar en la totalidad humana de modo formativo. La interiorización en sí y para otros en el trabajo se torna una aspiración por encontrar una identidad universal. Emerge la auto-consciencia construyendo su apropiación de la consciencia, pues el individuo concibe progresivamente que lo universal se constituye por leyes que posibilitan la socialidad a las que, luego, adoptan como condición de vida propia, entregándose a y apropiándose de lo universal. Hegel ve en la vida de la Grecia antigua este proceso en el concepto de ciudadanía. La ciudadanía contiene un concepto de ética permeado por el del "buen ser humano", carácter que le viene al individuo de su entrega a la membrecía y co-participación de un Estado cuya estructura se funda en leyes. Esta entrega constituye apenas el primer paso de una formación que tiene lugar en la medida en que esas leyes son asimiladas en la práctica, en sí y para sí. Formación que aparece de la superación de la esencia natural del individuo que aspira a adquirir una nueva naturaleza.

La naturaleza novedosa adoptada por el individuo trabajador que se subjetiviza asimila nuevas necesidades que se imponen como superlativas objetivamente, es decir, como provenientes de su exterior. La acción individual como acción humana deberá, ahora, disponer de la objetividad para la re-producción y desarrollo de esa nueva naturaleza vital, que es protegida por arte y religión. El arte no alcanza las "necesidades más elevadas", mientras que la religión llega a encontrar en el sentimiento el refugio que requiere para sobre-vivir a los embates de la objetividad moderna, y la subordinación de la religión al sentimiento puede guiar a la Pietät en tanto superación de la "piedad artística". En esta unidad dialéctica de "piedad artística" y "piedad religiosa", que se encuentra en el sentimiento, puede estar la base de la filosofía y de la vida subjetiva. 
En suma, en la indagación sobre lo divino es necesario referirse a lo humano como vía para llegar a un concepto de religión. Lo absoluto que lleva a la humanidad tiene por mediación la unidad aporética infinitud-finitud, en particular, si creemos que lo único infinito es lo finito y que este finito se refiere a la existencia en su sustancia y que ésta tenga como origen un sentido que se expresa al descubrirse la dirección hacia a dónde apunta el acontecer (Tat) de esa existencia. Es una cuestión que tiene una respuesta circular-formal: lo concreto de lo divino realizado en el hombre aparenta un proyecto determinado y la dirección que toma ese sentido es la humanidad misma. Lo Absoluto que se privilegia a sí mismo. Al aparecer lo humano como principio y fin de sí mismo, en la modernidad occidental, hay una tendencia hacia el subjetivismo en el que, al igual que se comporta con el sentimiento, remite la religión a un ámbito reducido, sometida por la humanidad autoconcebida subjetivamente. Emerge, ahora, una nueva concepción de la religión y, a la vez, por otra parte, surge el concepto de piedad en la teología que se ve amenazada por este embate modernosubjetivista. En la dimensión de la subjetividad moderna, el refugio de la piedad es el sentimiento concebido como ámbito de lo indeterminado y contrario a la subjetividad del individuo.

La subjetividad otorga a Dios y a la religión un carácter racional y determinante al concebir que uno y otra no tienen su fuente en el sentimiento, sino en el pensamiento posibilitando, así, la formación de una concepción de objetividad que niega la intención de reconocer lo propiamente subjetivo sin contenido material. La filosofía reconoce el fundamento objetivo de la subjetividad, una subjetividad que se "auto pone" mediante una actividad con bases objetivas. Este proceso subjetivoobjetivo hace del resultado una causa, formando un Absoluto que aparece, finalmente, como "la verdad y el resultado de todo" y, a la vez, lo "absolutamente primero" (Ginzo 1992:41). Este subjetivismo encuentra en el protestantismo y no en el cristianismo un sustento coherente $y$, mientras el cristianismo se auto-proclama la vida del proceso de subjetivación, el protestantismo constituye la forma en que éste proceso se vive en la realidad. Ambas formas de religión comparten el mismo ser Absoluto, un resultado que es causa, y ambas explican el momento histórico o la etapa de la teodicea en que la humanidad se encuentra a sí misma.

Para Ginzo la subjetivación de la religión en Hegel es acción humana, en general, y trabajo, en particular. Queda pendiente la humanidad del sentimiento. En La izquierda hegeliana como nueva fase de la ilustración, Ginzo expone la crítica al concepto de religión de Hegel por parte de sus discípulos de izquierda, desde Feuerbach a aquellos a quienes Marx en su Sagrada familia llamó Crítica crítica, desde los hermanos Bauer hasta Stirner. Ginzo omite la crítica de Marx y, por ello, no conecta con Der Geist des Christianismus und der Schicksal, que describe una evolución del judaísmo al cristianismo, que es básica para la Pietät.

Desde una perspectiva diferente a la de Marx, Derrida (Clamor) hizo esta conexión entre Sagrada Familia cristiana y Der Geist des Christianismus para encontrar en la obra de Hegel una conexión sustancial entre espíritu griego y cristianismo desde la familia. Para Derrida, la conexión espíritu griego-cristianismo se descubre en la superación del judaísmo mediante el amor. El amor contiene la conexión fraternal universal de la humanidad, y se concreta en la familia: Dios ya no es, como en el judaísmo, el amo y señor, sino el padre que provee de bienes por amor. El amor es el absoluto en donde tiene lugar la reconciliación y este se manifiesta, como en ninguna otra parte, en la familia. El espíritu griego mostró en la tragedia un apego amoroso tendente a la relación familiar. Con la familia amorosa adquiere sentido el concepto de propiedad (que adelantamos con Lukács), pues hace sentir en casa el lugar de llegada y morada, como la tierra. A ellas se conecta el individuo por 
amor, ahí concluye su errabunda naturaleza. El espíritu del cristianismo proviene de la Sagrada Familia (como también sugirió Steiner), lo que lo lleva a concebir que las formas de la ética corresponden a una cultura más universal, y específicamente la de la familia sería la forma de comunidad general en la que se establecen normas jurídicas, culturales y éticas.

El cristianismo apela a la humanidad y confluye en la filosofía: es religión de la revelación que escapa a la abstracción y la mera especulación. También apela a la conciliación fraternal entre lo finito y lo infinito, lo universal y lo individual, lo humano y lo divino, por esto puede conectar con el espíritu griego representado en la tragedia, que es un acontecimiento bello y catárquico (Hernández El conflicto trágico; Chen The Hegelian tragedy), contiene la compasión como resultado e impulso para la acción y caracteriza la vida cotidiana comunitaria y ético-política. Pero el espíritu griego-cristiano que se presenta a la filosofía tiende a perder el carácter revelador-reconciliador en el pensamiento y concepción modernas. Al individuo en este estadio se le objetiviza y esencializa desde su exterior, se le determina y pierde subjetividad. Es ejemplar la visión sobre la mujer y de la piedad, que la aparta del sentimiento y del pensamiento, con aspiración de objetividad, lo cual puede ocurrir desde la mujer misma como se advierte en el feminismo.

\section{Pietät y feminismo. Comunidad desde el conflicto al reconocimiento}

Hegel identificó la Pietät con la mujer en su legalidad orgánica guiando desde esa esencia individual hacia la conformación humana que alcanza su subjetividad con su acción real y concreta y encuentra su sustancia en el amor en familia, como forma básica de comunidad. Pero al identificar la Pietät con la mujer, Hegel planteó una serie de tesis polémicas que no pasaron desapercibidas al feminismo que reaccionó buscando la naturalidad de esta subjetivación y familiarización amorosa, su efectiva realización, en un proceso que podemos llamar post-filosófico y apegado a la ciencia, hasta separar la piedad de la mujer para buscarle otra identidad. Destacan en ese planteamiento feminista dos conceptos: culpa y reconocimiento.

Judith Butler (Antigone's claim) critica a Hegel siguiendo la antropología de Lévy-Strauss, mediante la cual concibe que la conformación familiar se explica por relaciones amorosas originadas en formas naturales gregarias intuitivas. La distinción de género aparece según el lugar que ocupan hombre y mujer en la formación familiar y del amor que ésta produce emerge un sentimiento de culpa que en Hegel aparece para imponer un estatus de género en el mundo: Hegel es, primero, un varón e impregna de esa naturaleza su filosofía, que demuestra un machismo radical al desaparecer (Efface) a Antígona de su obra.

Butler concibe a la familia desde el concepto de "kinship" (parentesco), que Hegel habría omitido, por lo que su concepto de familia como base natural y social humanas de la comunidad, tendría una representación más abstracta y especulativa. Hegel no habría advertido que el "parentesco" es aquella sustancia pre-sentimental y natural que él indaga, por lo que presenta a la familia como una reunión ética de individuos singulares en los cuales aún es dudoso que aparezca el amor. La naturalidad de la familia, según Butler, ha de guiar no a la igualdad sino a lo que es común y se superlativiza en la comunidad que necesita de un concepto de identidad. La comunidad, pensada no desde la filosofía, según la autora, en principio y en general es un artificio de individuos que deciden unirse y crear una sociedad. En Hegel, lo común de los individuos que con-forman la comunidad son normas éticas. Pero, según Butler, Hegel reprime la ley femenina, la de Antígona, 
primero, imponiéndole la de Creonte y, luego, devaluando el discurso de Antígona en favor del de aquel. El feminismo-antropológico derrumbaría esa ética hegeliana (Hernández El conflicto trágico), creando una base de perspectiva post-filosófica y moderna de concebir la práctica del pensamiento en favor de una concepción de la verdad ligada al realismo.

Martha Nussbaum (The fragility of goodness) lleva al extremo este realismo de Butler tratando el tema de Antígona y la piedad desde la perspectiva de la "simple y pura" expresión: llegar a lo más profundo de la expresión es describirla a ella misma y no a lo que expresa. La comunidad es la expresión de un profundo sentimiento de los individuos que les es común: la culpa, que contiene tres pasiones: el "rechazo, el remordimiento y lo doloroso" (revulsion, remorse and painful), que son los medios para llegar a ella y las que hacen que los humanos transiten en individualidades, sin que les una más identidad que la posibilidad de contenerlas, lo que les sitúa en el seno de un "conflicto". En Nussbaum el conflicto es lo propio de la tragedia y lo único que lo evita ("evoidance") es la racionalidad, la cual está ausente en la época de la Tragedia, lo que justificaría que la vida ética carezca de madurez en esos tiempos y Antígona representaría adecuadamente esta idea, lo que es posible ver leyéndola desde los coros, que expresan la época en que fue escrita dominada por el pensamiento de Parménides en la perspectiva de la identidad formal $(A=A)$ y no la dialéctica platónica $(A=B)$. Nussbaum se adhiere a la primera, Hegel sigue la segunda. Para Nussbaum, la conciliación se encuentra en la igualdad que aparece trágicamente en el conflicto entre Antígona y Creonte, en el que el concepto de culpa se torna abstracto debido a que la razón empuja para emerger en realizaciones particulares que forman una aparente substancia que supone una ruptura ética radical. Esta apariencia racional aparece cuando ni Antígona ni Creonte sienten remordimiento, rechazo o dolor por su conducta entre ellos, nadie es víctima, cada quien enfrenta una agresión que amenaza a su esencia ética singularizada con pretensiones de universalización. En este conflicto esencial se descubre una desvalorización de valores que llevaría al más elevado y fundamental de todos: el de justicia.

Esta racional negación de culpables y búsqueda de justicia lleva a una concepción objetivistapráctica que supera lo natural. Esta superación se refiere a la dimensión de la actividad humana que se convierte en tecnología. La tecnología es materialización del cambio de sensibilidad, denota que se han superado los temores a la naturaleza. Creonte representa esta sensibilidad-tecnológica, al defender sus normas para la creación de una nueva vida, la vida civil, que asume la evolución de la práctica humana en y para sí misma. Pero las creaciones humanas son medios de negación, más que de superación, de las formas de vida anteriores más apegadas a la naturaleza. Ahora, la libertad habrá de expresarse en el disfrute pleno de las nuevas creaciones humanas, entre las que se encontraría la ciudad como medio novedoso de aquella época. Antígona representa la debacle de la naturaleza debido al desarrollo humano-tecnológico, que representa y media la emergencia de la racionalidad humana que dominará la vida en general.

Esta racionalidad es un atributo individual que posibilita y construye lo social en Nussbaum, algo que solo es posible ver desde el conflicto y que Hegel evita con su concepto de absoluto. Según Nussbaum, Heráclito ya había adelantado este hecho mediante el concepto de Psuchē, o "la araña en medio de su telaraña", que descubre (según Nussbaum) que del conflicto surge una universal individualidad. Psuchē es la manifestación de la clara separación y determinación de lo singular en el que se concilia conflictivamente la multi-dimensionalidad de lo existente. El Coro en Antígona representa este Psuchē, como entidad aparte y espectador colectivo del acontecer de la vida de 
otros y ante el que se revela el conflicto social que se muestra en la tragedia y, en particular, en la relación de Creonte con Antígona. Creonte se relaciona con la luz que es la simplicidad propia de la superficialidad en la que se sitúa lo público; Antígona está en la privacidad de la familia inmersa en lo metafísico y la oscuridad. La simplicidad de Creonte es del ámbito de lo abierto y, como lo vería Hegel, de lo azaroso: simplemente nos llenamos de asombro ante lo que surge de la niebla y de lo impredecible de la naturaleza, que en Hegel sería lo objetivo y que ahora se tornaría (según Nussbaum) en lo subjetivo, poniendo a prueba al individuo en sus capacidades para enfrentar lo inesperado y actuar en consecuencia.

Esta subjetivación individual rompe la natural conexión con otros individuos debido a la acción y con la comunidad dialéctica hegeliana y, al desestimar la filosofía de Hegel, puede llegar a la expresión como propiciadora del sentimiento: sentir el sentimiento y estructurarlo en un concepto ya existente es lo femenino que abraza el ser "simplemente" consciente de la existencia de algo que se siente y nombramos, sin que sepamos qué lo produce y hacia a dónde se dirige. Esto forma la culpa como auto-conflicto individual. Este individuo singular en conflicto se opone a la comunidad y a la reconciliación y abandona la piedad.

Kimberly Hutchings (Living the contradictions) sin que lo explicite, regresa a Hegel rescatando la identidad entre mujer y piedad y precisando el tema del amor que plantea Butler. Para Hutchings la mujer es representación de la naturaleza y la familia es el espacio de posibilidad de secularización que se descubre al diferenciar las visiones católica y protestante. La unidad familiar aparece en el matrimonio: en el católico impuesta por la procreación como punto de enlace entre dos individuos libres; en el protestante lo sagrado es el amor. El punto de partida del catolicismo es objetivosubjetivo, externo a lo humano; el del protestantismo es humano, en formas de organización como la sociedad civil y el Estado.

El arte clásico-griego revela que la unidad de los individuos se debe a la ética y no a la religión. Hegel traslada la ética clásica-griega a su presente y la redefine artificialmente para llegar al concepto de piedad. En el terreno hegeliano la piedad se traduciría en "subversión de la naturaleza" (Horkheimer), representada por la mujer y, luego, reaparece en cada obra humana. Hutchings sugiere que la piedad es la parte sensible de lo humano que reaparece como sustancia conciliatoria al superar esencialmente el artificio: solo cuando éste afecta a la humanidad, la sensibilidad responde haciendo emerger la naturaleza humana. $Y$ esta naturaleza, con origen femenino, es clásica, trasciende en la historia y representa esa liberación de lo natural en lo humano, su naturaleza es subversiva y su valor la libertad. Hutchings es consciente de que el feminismo no está dispuesto a aceptar que esta posibilidad está planteada en la obra de Hegel.

Burke (The substance of ethical recognition) agrega el concepto de reconocimiento que alude a los de imagen y "representación" hegelianos. Burke concibe este reconocimiento como célula de la formación de una comunidad a la que llama "esfera de conflicto". En la modernidad, esa comunidad se presenta como "libre mercado". En el mercado acontece la normatización social entre individuos concebidos como propietarios privados que construyen el valor moderno de la igualdad que se revela en el acto del re-conocimiento mutuo y éste como el locus de la re-conciliación. Para ello, es menester la superación de propiedades naturales objetivo-subjetivas como el deseo, que tiene lugar en diferentes espacios de co-existencia humana. El deseo natural ha de ser opacado, por ejemplo, cuando es sexual si se presenta entre hermanos, y el de dominio sin importar el "parentesco". El 
reconocimiento estructura una concepción de convivencia natural-social. Así, para Burke, en Antígona la unidad de lo natural y lo civil aparece cuando ésta actúa desde el sentimiento y la relación biológica de hermandad, pero se diferencia identificándose a sí misma ante Creonte. En esta acción de Antígona, se descubre el proceso de sublación hegeliana, que Burke traduce del concepto de Aufhebung, proceso en el que se eleva y cancela a la vez una nueva dimensión en la que lo divino y lo terreno se convierten en dos polos de un mismo cuerpo natural que establece la mutua dependencia. Para Burke en la relación de reconocimiento entre hermanos las mujeres se universalizan negando toda particularidad. Así desaparece el conflicto y emerge la reconciliación.

Según Burke es propio de la libertad capitalista la posibilidad de conformación de la familia y la comunidad sobre la base de las capacidades de los individuos que adquieren por ellas un cierto carácter para relacionarse con el exterior. Este tránsito de lo individual a lo social desde la familia en Antígona se presenta como tránsito del dominio de la piedad a la objetividad de la sociedad en abstracto, de la legalidad sostenida en la identidad natural en su pureza a la identidad objetiva debida a una legalidad que se construye con base en la determinación exterior y objetiva que se traduce en la acción de individuos como Antígona y Creonte. Piedad y acción se advierten como medios diferenciados de construcción de humanidad en su pureza, que aparecen reconocidas como representaciones particulares y concretas.

\section{Conclusión}

Las interpretaciones de la lectura que Hegel hizo de la Antígona de Sófocles se tornan menos filosóficas y más científico sociales en la medida en que de esa lectura emergen particularidades que hacen de lo universal una realidad, concretando la superación hegeliana de la dialéctica platónica, acontecimiento que le interesa a Hegel más por su relación con la formación social que con la especulación filosófica y le resta misticismo al origen de la filosofía: arte y religión.

El marco conceptual hegeliano de la formación social adquiere carácter humano desde el término Pietät que Hegel utiliza en su lectura de aquella obra de Sófocles, cuando se descubre la estructura universal de las diversas formas sociales en sus particulares manifestaciones reales como familia y Estado, mediadas por la sociedad, en cuya disquisición se descubre el riesgo de des-humanización de un constructo, contradictoriamente, propiamente humano.

Este artículo intentó poner de manifiesto estos hechos acercándose al concepto de Pietät exponiendo algunas destacadas interpretaciones de la lectura que Hegel hizo de Antígona, y de las que, como dice Butler, la obra de Hegel es punto de partida. Estas interpretaciones, rondan el positivismo del que parecen escapar al buscar en la ética, la historia y la antropología, en los valores de la justicia, libertad e igualdad, la secularidad de la sociedad y a ésta en cuanto tal, llegando a un evolucionismo que lleva al límite de restar humanidad a la objetivización del individuo en su acción para la vida. Pero estas interpretaciones ponen de manifiesto la importancia de la Pietät en su relación con esta objetivización que, universalmente, se manifiesta en formas sociales particulares. Destaca, también, que para llegar al fondo de ese humanismo se precise de una visión de la mujer relativa al origen de la humanidad, que Hegel identifica con la Pietät, tomada como organicidad dada por leyes, lo cual abre un espacio al estudio del lugar de la mujer en la sociedad. La Pietät, en suma, es un marco de referencia para la producción de conceptos que delimiten al ser social desde una perspectiva comunitaria y humana. 


\section{Bibliografía}

Bloch, E. 1983. Sujeto-Objeto. El pensamiento de Hegel. Fondo de Cultura Económica.

Ginzo, A. 1992. En torno a la filosofía de la religión de Hegel. En G.W.F. Hegel. El concepto de religión, pp. 7-56. Fondo de Cultura Económica.

Hegel, G.W.F. 1833. Grundlinien der philosphie des Rechts oder naturrecht und Stattswissenschaft. Ullstein.

Hegel, G.W.F. 1997. Introducción a la estética. Ediciones Península.

Hegel, G.W.F. 2005. Enciclopedia de las ciencias filosófica. Alianza Editorial.

Recibido el 6 Dic 2020

Aceptado el 14 Feb 2021 